\title{
DOSES E MODOS DE ADUBAÇÃO COM MANGANÊS E SEUS EFEITOS NA PRODUÇÃO DA CULTURA DO ARROZ ${ }^{(\mathbf{1})}$
}

\author{
G. D. PEREIRA(2), J . C. BERTONI (2), \\ J. G. CARVALHO(3) \& A. R. MORAIS ${ }^{(4)}$
}

\begin{abstract}
RESUMO
O presente trabalho foi realizado em casa de vegetação, com o objetivo de estudar doses e modos de aplicação de manganês sobre variáveis vegetativas e componentes da produção de cultivares de arroz de terras altas. Os tratamentos constaram de cinco doses de manganês, sendo quatro aplicadas via solo $(0,4,8$ e $16 \mathrm{mg} \mathrm{dm}^{-3}$ de solo) e uma via foliar (três aplicações de $4 \mathrm{~g} \mathrm{~L}^{-1}$ ), e dois cultivares de arroz de sequeiro (Canastra e Confiança). $O$ delineamento experimental utilizado foi o inteiramente casualizado, com quatro repetições, com os tratamentos dispostos em esquema fatorial $2 \times 5$. Cada parcela foi constituída por um vaso com $8 \mathrm{dm}^{3}$ de solo (Latossolo Vermelho-Amarelo, sob vegetação primitiva de cerrado), com seis plantas. Comparando a aplicação de $8 \mathbf{~ m g ~ d m}^{-3}$ via solo e via foliar, nas dosagens recomendadas pela literatura, notou-se que a aplicação via solo propiciou os maiores incrementos nos valores das variáveis estudadas. As máxi mas produções das variáveis for am obtidas pela aplicação de 8,75 a $9,93 \mathrm{mg} \mathrm{dm}^{-3}$ de $\mathrm{Mn}$ via solo, evidenciando que, para as condições estudadas, a dose recomendada pela literatura mostrou-se adequada, visto que os valores supracitados ficam na faixa de pequenos incrementos. Houve diferença, embora não muito acentuada, entre os cultivares testados no tocante à aplicação de manganês. $O$ cultivar Canastra mostrou-se mais responsivo, apresentando maior produção de grãos cheios que o Confiança a partir da aplicação de $6,81 \mathrm{mg} \mathrm{dm}^{-3}$ de $\mathrm{Mn}$ via solo. $\mathrm{O}$ efeito negativo das maiores doses de $\mathrm{Mn}$ via solo sobre as características avaliadas deve estar associado à deficiência de Fee não à toxidez de Mn propriamente dita.
\end{abstract}

Termos de indexação: Oryza sati va, Mn, adubação foliar, adubação via solo.

(1) Recebido para publicação em abril de 2000 e aprovado em fevereiro de 2001.

(2) Graduando da Universidade Federal de Lavras - UFLA. Caixa Postal 37, CEP 37.200-000 Lavras (MG). Bolsista da CAPES. E-mail: bertoni@ufla.br

(3) Professor do Departamento de Ciência do Solo, UFLA.

(4) Professor do Departamento de Ciências Exatas, UFLA. 


\title{
SUMMARY: DOSES AND METHODS OF MANGANESE FERTILIZATION AND ITS EFFECT UPON THE PRODUCTION OF UPLAND RICE
}

\begin{abstract}
This work was conducted under greenhouse conditions to evaluate how doses and methods of manganese $(\mathrm{Mn})$ application may affect vegetativecharacteristics as well as the production of upl and rice The treatments consisted of five manganese doses appl ied either via soil $\left(0,4,8\right.$, and $\left.16 \mathrm{mg} \mathrm{dm}^{-3}\right)$ or leaf (3 $4 \mathrm{~g} \mathrm{~L}^{-1}$ applications), associated with two rice cultivars (Canastra and Confiança). The experiment was randomly designed, with four replications, in a $2 \times 5$ factorial scheme Each pl ot consisted of a recipient containing $8 \mathrm{dm}^{3}$ of soil (a Red-Yellow Latosol, which is an Oxisol), with six plants. The foliar application of $\mathrm{Mn}$ at the recommended dosage resulted in a smaller production of rice when compared with the soil application rate of $8 \mathrm{mg} \mathrm{dm}^{-3} \mathrm{Mn}$, which is the most recommended soil application rate found in the literature Maximum production was obtained for soil application rates varying from 8.75 to $9.93 \mathrm{mg} \mathrm{dm}^{-3} \mathrm{Mn}$ soil, which fall in the so-called small increments range Thericecultivars had a slightly different responseto $\mathrm{Mn}$ application with Canastra responding better than Confiança. Thenegative effect of thelargest doses of $\mathrm{Mn}$ via soil on theevaluated parameters should beassociated to Fe deficiency and not to $\mathrm{Mn}$ toxicity.
\end{abstract}

Index terms: Oryza sativa, Mn, foliar fertilization, soil fertilization.

\section{INTRODUÇÃO}

O arroz de sequeiro é plantado principalmente nos solos do cerrado e concentra-se nas regiões do triângulo, sul e noroeste de Minas Gerais, nesta ordem, respectivamente, ocupando $65 \%$ (44.200 ha) deárea cultivada entreas 10 regiões de planejamento do estado (IBGE, 1999).

A cultura do arroz de sequeiro foi considerada, até pouco tempo, como uma cultura desbravadora, e sua expansão, no Brasil l, está ligada sobretudo à sua rusticidade. As mudanças começaram a aparecer apenas nesta década, quando o Centro Nacional de Pesquisa de Arroz e Feijão EMBRAPA-CNPAF colocou à disposição dos produtores variedades de sequeiro mais produtivas e com grãos mais al ongados, como a Canastra ea Confiança, chamadas de "agulhinha de sequeiro" ou de "terras altas" (Toledo, 1999).

Dentro das limitações de fertilidadeimpostas pel o solo das áreas de cerrado está o baixo teor de manganês disponível. Sanzonowicz (1995) considera crítico o nível de $5,0 \mathrm{mg} \mathrm{dm}^{-3}$ de $\mathrm{Mn}$ (extrator Mehlich-1), em amostras de solo com $\mathrm{pH} \mathrm{H}_{2} \mathrm{O} 6,0$, existindo a possibilidade de ocorrer deficiência desse nutriente em cerca de $1 / 3$ dos solos desta região, principal mente nos estados de Goiás, Minas Gerais e no Distrito Federal.

Não existem, ainda, estudos relacionados com a avaliação do nível crítico de manganês para os solos do cerrado (Lopes \& Guilherme, 1994). A deficiência desse nutriente tem sido agravada por diversos fatores, dentre os quais se destacam: o uso excessivo decalcário, decorrentederecomendações inadequadas, a não-observação do período de efeito residual da calagem e até mesmo a incorporação do calcário recomendado para $0-20 \mathrm{~cm}$ na camada superficial do sol o, 0-10 cm, o que dobra a quantidade aplicada nessa profundidade. Segundo estimativas de Sanzonowicz (1995), a deficiência de manganês já ocorre em mais de $10 \%$ das lavouras do cerrado.

Várias estratégias usadas para prevenir ou corrigir as deficiências de manganês nas plantas visam superar a imobilização do $\mathrm{Mn}$ aplicado, aumentando o contato do el emento com as raízes, e promover sua redistribuição na planta. A mobilidade do $\mathrm{Mn}$ no solo é lenta, e seu aproveitamento pela planta depende da absorção pelas raízes, que, por sua vez, é governada pela disponibilidade do elemento na interface solo-raiz.

O manganês não é facilmente redistribuído na planta e sintomas de deficiência surgem em fol has novas sehouver restrição na disponi bilidadedurante o desenvol vimento da planta, mesmo que as fol has vel has contenham altas concentrações do el emento (Loneragan, 1988).

Apesar de ser o $\mathrm{Mn}^{+2}$ absorvido pelas raízes preferencialmente transportado para os pontos de crescimento (fol has, raízes e sementes) (Reuter et al., 1988), sua baixa mobilidade no floema de plantas vem dar suporte à base fisiológica para a falta de sucesso da adubação foliar com $\mathrm{Mn}$, em plantas deficientes, dada a menor redistribuição do $\mathrm{Mn}^{+2}$ aplicado à folhagem para aqueles tecidos. Sob condições de deficiência, a absorção do nutriente propicia uma recuperação inicial, mas, caso o estresse continue ou se repita, a formação da nova fol hagem é comprometida. 
Baseado nestes princípios, recomendam-se menores quantidades aplicadas com maior freqüência (Hannam \& Riggs, 1985). Os resultados obtidos por Mann (1999) comprovaram esta recomendação, pois demonstrou que o parcel amento da pulverização nos estádios de desenvol vimentoV4 eV8 (quatro e oito trifól ios com folíol os desdobrados, respectivamente) da soja foi o mais eficiente, apresentando incremento na produtividade superior a $50 \%$.

Considerando a importância da cultura do arroz para o Brasil e para o estado de Minas Gerais, bem como os poucos estudos que a associam à nutrição com manganês, o presente trabalho teve como objetivos estudar as respostas de dois cultivares de arroz de terras altas a doses e modos de aplicação de manganês, tanto via sol o como via foliar, com vistas em obter resultados sobrea dosei deal via solo esobre a eficiência da adubação foliar na cultura do arroz.

\section{MATERIAL E MÉTODOS}

O experimento foi realizado em casa de vegetação doDepartamento de Ciência do Solo da Universi dade Federal de Lavras, em Lavras (MG), utilizando um Latossolo Vermel ho-Amarelo textura média, sob vegetação primitiva de cerrado, coletado no município de Ijaci (MG), na camada de $0-20 \mathrm{~cm}$ de profundidade.

As amostras foram secas ao ar e passadas em peneira com malha de 5,0 mm de abertura, sendo retiradas subamostras para caracterização química e física, conforme orientações da EMBRAPA, 1997, apresentando os seguintes atributos: $\mathrm{Al}=$ $0,0 \mathrm{cmol}_{\mathrm{c}} \mathrm{dm}^{-3} ; \mathrm{Ca}=5,3 \mathrm{cmol}_{\mathrm{c}} \mathrm{dm}^{-3} ; \mathrm{Mg}=$ $2,0 \mathrm{cmol}_{\mathrm{C}} \mathrm{dm}^{-3} ; \mathrm{K}=0,15 \mathrm{cmol}_{\mathrm{C}} \mathrm{dm}^{-3} ; \mathrm{P}=5,0 \mathrm{mg} \mathrm{dm}^{-3}$; $\mathrm{H}+\mathrm{Al}=1,5 \mathrm{cmol}_{\mathrm{c}} \mathrm{dm}^{-3} ; \mathrm{Mn}=3,9 \mathrm{mg} \mathrm{dm}^{-3} ; \mathrm{Fe}=$ $36,7 \mathrm{mg} \mathrm{dm}^{-3} ; \mathrm{Zn}=2,5 \mathrm{mg} \mathrm{dm}^{-3} ; \mathrm{Cu}=1,1 \mathrm{mg} \mathrm{dm}^{-3}$; M.O. $=31 \mathrm{~g} \mathrm{~kg}^{-1} ; \mathrm{pHH}_{2} \mathrm{O}=6,4$; areia $=430 \mathrm{~g} \mathrm{~kg}^{-1}$; silte $=320 \mathrm{~g} \mathrm{~kg}^{-1}$; argila $=250 \mathrm{~g} \mathrm{~kg}^{-1}$.

A pós a secagem e peneiração, $8 \mathrm{dm}^{3}$ de sol o foram acondicionados em vasos, sem sistema de drenagem, com capacidade para $10 \mathrm{dm}^{3}$, constituindo a unidade experimental.

O delineamento experimental utilizado foi o inteiramente casualizado, com quatro repetições, sendo os tratamentos dispostos em esquema fatorial $2 \times 5$. Os fatores constituíram-se de dois cultivares de arroz de sequeiro (Canastra e Confiança - cujas características podem ser vistas em Soares et al., 1999) e cinco doses de manganês, sendo quatro aplicadas via solo $\left(0,4,8,16 \mathrm{mg} \mathrm{dm}^{-3}\right.$ de solo), em dose única antecipadamente ao plantio, e uma via foliar (31,25 mL de uma solução de concentração igual a $4 \mathrm{~g} \mathrm{~L}^{-1}$, por aplicação), parcelada em três diferentes épocas ( 25 dias após a germinação e as demais seguindo intervalo regular de 25 dias).
Para ambas as adubações, utilizou-se o $\mathrm{MnSO}_{4} \cdot 4 \mathrm{H}_{2} \mathrm{O}$ puropara análise(PA). As doses aplicadas via solo e foliar foram baseadas em Neves (1994) e Fageria et al. (1995), considerando adequada a aplicação via solo de $8 \mathrm{mg} \mathrm{dm}^{-3}$ e a fol iar com $4 \mathrm{~g} \mathrm{~L}^{-1}$. As aplicações foliares foram realizadas com auxílio de plásticos, ao redor e na superfície dos vasos, para que fossem evitados a deriva e o escorrimento da solução aplicada no solo.

Como adubação básica foram aplicados, em $\mathrm{mg} \mathrm{dm}^{-3}, 300$ de N, 200 de P, 240 de K, 30 de Mg, 0,5 de $\mathrm{B}, 1,5$ de $\mathrm{Cu}, 5$ de $\mathrm{Zn}$ e 0,1 de $\mathrm{Mo}$, tendo como fontes $\mathrm{CO}\left(\mathrm{NH}_{2}\right)_{2}$ e $\mathrm{NH}_{4} \mathrm{NO}_{3}, \mathrm{Ca}\left(\mathrm{H}_{2} \mathrm{PO}_{4}\right)_{2} \cdot \mathrm{H}_{2} \mathrm{O}, \mathrm{KCl}$, $\mathrm{MgSO}_{4} .7 \mathrm{H}_{2} \mathrm{O}, \mathrm{H}_{3} \mathrm{BO}_{3}, \mathrm{CuSO}_{4} \cdot 5 \mathrm{H}_{2} \mathrm{O}, \mathrm{ZnSO}_{4} \cdot 7 \mathrm{H}_{2} \mathrm{O}$ e $\left(\mathrm{NH}_{4}\right)_{6} \mathrm{M} \mathrm{o}_{7} \mathrm{O}_{24} \cdot 4 \mathrm{H}_{2} \mathrm{O}$, respectivamente.

Os nutrientes foram aplicados em forma de solução e misturados ao solo, o qual permaneceu incubado por 25 dias, mantendo-se a umidade do solo entre 60 e $80 \%$ do volume total de poros - VTP. O nitrogênio e o potássio foram parcelados em três aplicações iguais, uma no plantio e as outras aos 35 e 55 dias da emergência das plântulas. Para o nitrogênio, no plantio, a uréia foi utilizada como fonte; em cobertura, a fonte utilizada foi o $\mathrm{NH}_{4} \mathrm{NO}_{3}$, fornecendo, por aplicação, $100 \mathrm{mg} \mathrm{dm}^{-3}$ deN desolo.

As sementes de arroz for am tratadas com sol ução de hipocl orito de sódio a 1\% e semeadas 10 sementes por vaso no dia 12 de dezembro de 1998. Após a germinação, foram deixadas seis plantas uniformes e vigorosas por vaso.

A umidade do sol o foi mantida entre 60 e $80 \%$ do volume total de poros do solo (VTP), usando-se água desmineralizada, sendo o controlefeito por pesagens diárias dos vasos.

Aos 70 dias da germinação, fase imediatamente anterior à iniciação da panícula em fase vegetativa, foram coletadas três plantas por vaso para análise foliar. Segundo Barbosa Filho \& Fageria (1980), as fol has mais novas dessa fase, com desenvol vimento normal esem entrar em senescência, refletem, com maior precisão, o estado nutricional da planta de arroz. Estas fol has foram lavadas em água destilada e deionizada, levadas a secar até atingir massa constante em estufa de circulação forçada de ar a $60^{\circ} \mathrm{C}$, pesadas e moídas em moinho tipo Wiley para subseqüente digestão nítricoperclórica para determinação dos macro e micronutrientes, conforme procedimentos descritos por Malavol ta et al. (1997).

As outras três plantas foram mantidas nos vasos até o final do ciclo para as avaliações do efeito do manganês sobre a matéria seca, dos componentes da produção (relação panícula/perfilho e percentagem de grãos cheios) e dos rendimento de grãos.

As características avaliadas tiveram seus dados submetidos à análise de variância, segundo o modelo baseado em Banzatto \& Kronka (1992), para os experimentos fatoriais. 
Quando houve efeito significativo das doses de manganês via solo, foram ajustadas equações de regressão às diversas variáveis, sendo feita a escol ha dos modelos de regressão de acordo com a significância dotesteF ecom os valores do coeficiente de determinação $\left(R^{2}\right)$. Para comparar as médias dos tratamentos, empregou-se o teste de Dunnett, comparando-se a adubação foliar com os demais tratamentos de adubação via solo.

Tanto a análise de variância como os ajustes de equações de regressão foram efetuados pelo programa SANEST (Zonta \& Machado, 1991).

\section{RESULTADOS E DISCUSSÃO}

Um resumo da análise de variância para as variáveis influenciadas por algum dos tratamentos e, ou, suas interações, está apresentado no quadro 1.

Diferenças significativas quanto à matéria seca da raiz foram observadas entre cultivares, tendo o cultivar Confiança apresentado maior massa média $(70,59 \mathrm{~g})$ em relação à do cultivar Canastra $(58,74 \mathrm{~g})$. A adubação com manganês influenciou a matéria seca de raiz, havendo efeito de doses via sol o e modo de aplicação. Fica evidenciado, na figura la, que no tratamento em que não se aplicou manganês obtevese a menor produção de matéria seca de raiz e que, com aplicação da dose de $8,0 \mathrm{mg} \mathrm{dm}^{-3}$ de $\mathrm{Mn}$, esta variável esteve próxima de um ótimo desejável, ou seja, máxima matéria seca de raiz, que, no caso, ocorreu em 9,14 $\mathrm{mg} \mathrm{dm}^{-3}$ de $\mathrm{Mn}$. J á coma maior dose aplicada, $16 \mathrm{mg} \mathrm{dm}^{-3} \mathrm{de} \mathrm{Mn}$, foi verificado um efeito depressivo da aplicação de $\mathrm{Mn}$ sobre o crescimento de raízes.
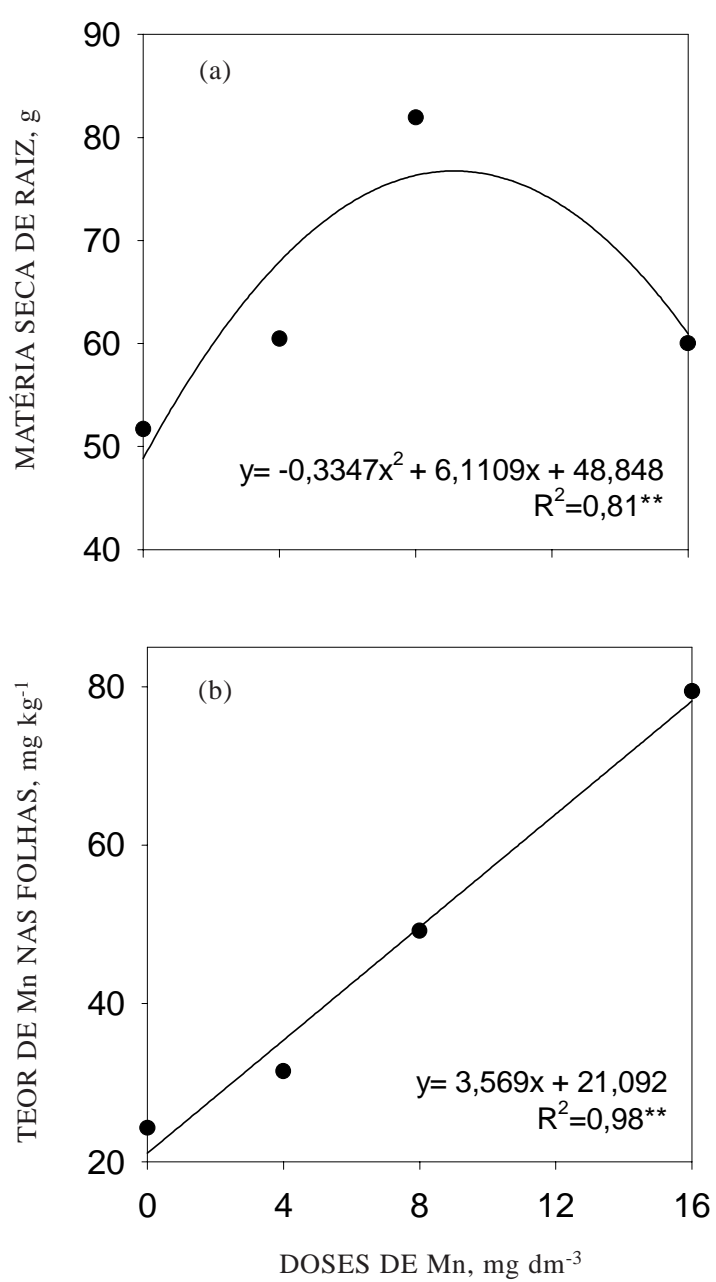

Figura 1. Matéria seca de raiz e teor foliar de Mn, considerando as doses de Mn aplicadas ao solo, para ambos os cultivares estudados.

Quadro 1. Resumo da análise de variância para as variáveis que foram influenciadas pelos tratamentos

\begin{tabular}{|c|c|c|c|c|c|c|}
\hline Causa da variação & G.L. & $\begin{array}{c}\text { Matéria } \\
\text { seca de raiz }\end{array}$ & $\begin{array}{c}\text { Relação } \\
\text { panícula/perfilho }\end{array}$ & $\begin{array}{l}\text { Grãos } \\
\text { cheios }\end{array}$ & $\begin{array}{l}\text { Produção } \\
\text { total de grãos }\end{array}$ & $\begin{array}{l}\text { Teor } \\
\text { de Mn }\end{array}$ \\
\hline & & g & & $\%$ & $g$ & $\mathrm{mg} \mathrm{kg}^{-1}$ \\
\hline Cultivar (C) & 1 & $* *$ & $* *$ & $* *$ & ns & $* *$ \\
\hline Adubação Mn (A) & (4) & $* *$ & $* *$ & $* *$ & $* *$ & $* *$ \\
\hline Dose Mn solo (DS) & 3 & $* *$ & $* *$ & $* *$ & $* *$ & $* *$ \\
\hline Foliar vs DS & 1 & $* *$ & ns & $*$ & ns & $* *$ \\
\hline$C \times A$ & $(4)$ & ns & ns & $*$ & $* *$ & ns \\
\hline $\mathrm{DS} \times \mathrm{C}$ & 3 & ns & ns & $*$ & $* *$ & ns \\
\hline (Foliar vs DS) $\times$ C & 1 & ns & ns & ns & ns & ns \\
\hline Resíduo & 30 & -- & -- & -- & -- & -- \\
\hline Média & & 64,66 & 0,924 & 79,18 & 40,28 & 44,72 \\
\hline C.V. (\%) & & 5,10 & 2,88 & 2,51 & 5,67 & 9,03 \\
\hline
\end{tabular}

\footnotetext{
*, ** e ns: Significativos a 5 e 1\% e não-significativo.
} 
Quanto à concentração de $\mathrm{Mn}$ na parte aérea das plantas, observou-se um efeito linear dependendo da dose aplicada ao solo (Figura 1). Percebeu-se atenção que na dose mais alta de $\mathrm{Mn}$ aplicada ao solo (16 $\left.\mathrm{mg} \mathrm{dm}^{-3}\right)$ a concentração deste elemento estava dentro dos níveis adequados, conforme Clarkson (1988).

Comparando os teores foliares de $\mathrm{Mn}$ obtidos com aquel es consi derados deficientes, críticos, adequados e tóxicos, respectivamente, em mg kg-1: <20; 20 a 30; 30 a 600; > 1000, segundo Fageria et al. (1995), observou-se que as duas menores doses de $\mathrm{Mn}$ aplicadas propiciaram teores dentro da faixa considerada crítica, justificando as menores produções de raízes e os sintomas visuais de deficiência observados no decorrer do desenvolvimento da cultura, os quais se manifestaram, de maneira mais expressiva, na ausência da aplicação de $\mathrm{Mn}$, na forma de clorose internerval das folhas mais novas, com as faixas amareladas mais intensas nas pontas eavançando para a base das fol has, surgindo manchas necróticas na lâmina foliar com o avanço da idade, sintomas semelhantes aos descritos por Fornasieri Filho \& Fornasieri (1993).

Deve-seressaltar que, de acordo com oteor inicial de $\mathrm{Mn}$ no solo (3,9 $\mathrm{mg} \mathrm{dm}^{-3}$ - teor médio de acordo com Raij et al., 1996), não se esperava deficiência de $\mathrm{Mn}$. Entretanto, segundo os próprios autores supracitados, a interpretação da análise de sol o para micronu-trientes pode ser aprimorada pela consideração de diferentes espécies vegetais. Nas tabelas de adubação, a interpretação da análise de solo é incluída para as culturas em que têm sido constatadas deficiências freqüentes, o que não tem sido o caso do arroz em relação ao manganês. Entretanto, o teor foliar observado na testemunha (ausência da aplicação de manganês) enquadrado na faixa crítica, já comentada, não condiz com oteor inicial tido como médio, o que mostra a necessidade de maior número de estudos que envolvam a fertilidade do sol o e nutrição de plantas de arroz com o manganês.
Com a aplicação de 8 e $16 \mathrm{mg} \mathrm{dm}^{-3}$ de $\mathrm{Mn}$, a concentração de $\mathrm{Mn}$ na parte aérea está dentro da faixa considerada adequada conforme Fageria et al . (1995), o que se opõe a um possível efeito tóxico do $\mathrm{Mn}$, depreciando o crescimento de raízes. Cabe ressaltar que o $\mathrm{Mn}$, dentre os vários elementos essenciais, é o que apresenta, na literatura, a maior amplitude de teores considerados adequados (30 a $600 \mathrm{mg} \mathrm{kg}^{-1}$ ).

A produção de matéria seca de raiz diferiu significativamente quanto ao modo de aplicação. Nas doses de 4 e $16 \mathrm{mg} \mathrm{dm}^{-3}$ de $\mathrm{Mn}$, via solo, a produção foi menor que quando se usou a aplicação foliar (4 aplicações de $4 \mathrm{mg} \mathrm{dm}^{-3}$ ). Por outro lado, a aplicação da dose de $8 \mathrm{mg} \mathrm{dm}^{-3}$ de $\mathrm{Mn}$, via solo, propiciou maior produção de matéria seca (Quadro 2).

Dentre os componentes de produção avaliados, optou-se por discutir aqueles resultados que os associam, como é o caso da rel ação panícula/perfilho (perfilho produtivo) ea percentagem de grãos cheios, queenvolveo número de grãos cheios eototal degrãos, que, ao fazerem parte dos componentes da produção, definem orendimento de grãos e, conseqüentemente, a produção do arroz (I shizuka, 1971).

Observaram-se diferenças significativas entre os cultivares (Quadro 1), sendo a relação panícula/ perfilho (índice de perfilho produtivo) do cultivar Confiança $(0,944)$ superior à de Canastra $(0,905)$.

Ainda com relaçãoà panícula/perfilho, a adubação com manganês aplicada via solo influenciou significativamente essa variável, mas o modo de aplicação não a afetou. Houve um aumento do índice de perfilho produtivo com o incremento das doses de $\mathrm{Mn}$ via solo até $9,76 \mathrm{mg} \mathrm{dm}^{-3}$ de $\mathrm{Mn}$, decrescendo desdeentão(Figura 2a). Entretanto, essa diminuição dos perfilhos produtivos não era esperada, por encontrar-se o teor de Mn foliar, aproximadamente de $56 \mathrm{mg} \mathrm{kg}^{-1}$, dentro da faixa considerada adequada para a cultura do arroz (Fageria et al., 1995).

Quadro 2. Valores da matéria seca da raiz eíndice de perfil ho produtivo, comparados pelo teste de Dunnett, entre as aplicações via foliar e as doses via solo de $\mathrm{Mn}^{+2}$, nas plantas de arroz

Adubação de manganês

Aplic. Foliar $3 \times\left(4 \mathrm{~g} \mathrm{~L}^{-1}\right.$ de $\left.\mathrm{Mn}\right)$

Solo $\left(0,0 \mathrm{mg} \mathrm{dm}^{-3}\right.$ de $\left.\mathrm{Mn}\right)$

Solo (4,0 $\mathrm{mg} \mathrm{dm}^{-3}$ de $\mathrm{Mn}$ )

Solo (8,0 $\mathrm{mg} \mathrm{dm}^{-3}$ de $\mathrm{Mn}$ )

Solo (16,0 $\mathrm{mg} \mathrm{dm}^{-3}$ de $\mathrm{Mn}$ )

D.M.S.
Matéria seca da raiz (g)

69,21

$51,66 * *$

$60,44 * *$

$81,94 * *$

$60,10 * *$

5,36
Índice de perfilho produtivo

0,934

$0,856 * *$

$0,925^{\text {ns }}$

$0,981 * *$

$0,926^{\text {ns }}$

0,04

** D.M.S. a 1\%; *D.M.S. a 5\% e ns = não-significativo. 
Os resultados aqui encontrados são cor roborados pelos relatos de Longnecker et al. (1988), os quais observaram, em cevada, que a deficiência de $\mathrm{Mn}$ prolonga o período de perfilhamento, resultando, entretanto, na maioria, improdutivos. Segundo Barbosa Filho (1987), um maior perfilhamento, originando maior número de panículas férteis, são pré-requisitos para altas produções. A dose recomendada pela literatura de $8 \mathrm{mg} \mathrm{dm}^{-3}$ já se encontra na faixa de pequenos incrementos (Figura 2a), sendo, portanto, a dose que propiciou o melhor índice de perfilhos produtivos dentre as estudadas.

Quanto ao modo de aplicação (Quadro 2), a aplicação de $8 \mathrm{mg} \mathrm{dm}^{-3}$ via solo propiciou maior índice de perfilho produtivo, superando a aplicação foliar que só levou a resultados maiores que os do tratamento no qual não houve aplicação com Mn (dose 0).

A percentagem de grãos cheios (no. de grãos cheios/no. total de grãos) foi influenciada por quase todas causas de variação (Quadro 1). Dentre os cultivares, o Confiança $(82,83 \%)$ superou o Canastra (75,52\%), permanecendo a tendência verificada para as outras variáveis estudadas, como a matéria seca de raiz e a relação panícula/perfilho, em que o cultivar Confiança sempre apresentou seus valores médi os superiores aos do Canastra. Quanto às doses aplicadas via solo, os cultivares comportaram-se de maneira diferenciada (Quadro 1), tendo, em ambas, com o aumento das doses de $\mathrm{Mn}$, ocorrido aumento da percentagem de grãos cheios até um máximo (Confiança $=8,85 \mathrm{mg} \mathrm{dm}^{-3}$; Canastra $=9,81 \mathrm{mg} \mathrm{dm}^{-3}$ ), decrescendo desde então (Figura 2b). Conforme relatado anteriormente, esses resultados não eram esperados, uma vez que os teores foliares de $\mathrm{Mn}$ não alcançaram níveis tóxicos segundo as faixas descritas na literatura. Com relação ao modo de aplicação, embora os valores absolutos fossem distintos, em ambos os cultivares, a aplicação de $8 \mathrm{mg} \mathrm{dm}^{-3}$ de $\mathrm{Mn}$ via solo proporcionou maiores percentagens de grãos cheios que a aplicação foliar (Quadro 4).

Quanto à produção total de grãos cheios, chama a atenção o fato de não terem ocorrido diferenças significativas entre os cultivares testados, com relaçãoà média geral dos tratamentos, principalmente por ser o cultivar Confiança menos produtivo do que

Quadro 3. Valores dos teores foliares de Mn nos cultivares de arroz Canastra e Confiança

\begin{tabular}{|c|c|c|c|}
\hline \multirow[b]{2}{*}{ Adubação de manganês } & \multicolumn{3}{|c|}{ Teor foliar de Mn (mg kg-1) } \\
\hline & Canastra & Confiança & Média \\
\hline Aplic. Foliar $3 x(4 \mathrm{~g} \mathrm{Mn/L})$ & 39,22 & 39,35 & $39,29 * *$ \\
\hline Solo $\left(0,0 \mathrm{mg} \mathrm{Mn} / \mathrm{dm}^{3}\right)$ & 21,65 & 26,87 & $24,26^{* *}$ \\
\hline Solo (4,0 mg Mn/dm³) & 27,47 & 35,45 & $31,46^{* *}$ \\
\hline Solo $\left(8,0 \mathrm{mg} \mathrm{Mn} / \mathrm{dm}^{3}\right)$ & 45,87 & 52,47 & $49,17^{* *}$ \\
\hline Solo (16,0 mg Mn/dm³) & 78,50 & 80,31 & $79,40 * *$ \\
\hline DMS & & & 6,56 \\
\hline
\end{tabular}

Quadro 4. Valores da percentagem de grãos cheios e produção total de grãos cheios, comparados pelo teste de Dunnett entre as aplicações via foliar e as doses via solo de $\mathrm{Mn}^{+2}$, nos cultivares de arroz Canastra e Confiança

\begin{tabular}{|c|c|c|c|c|}
\hline \multirow{2}{*}{ Adubação de manganês } & \multicolumn{2}{|c|}{ Percentagem de grãos cheios (\%) } & \multicolumn{2}{|c|}{ Produção total de grãos cheios (g) } \\
\hline & Canastra & Confiança & Canastra & Confiança \\
\hline Aplic. Foliar $3 x\left(4 \mathrm{~g} \mathrm{~L}^{-1}\right.$ de $\left.\mathrm{Mn}\right)$ & 77,72 & 83,49 & 40,30 & 39,78 \\
\hline Solo $\left(0,0 \mathrm{mg} \mathrm{dm}^{-3}\right.$ de $\left.\mathrm{Mn}\right)$ & $67,70^{* *}$ & $79,21 *$ & $29,48^{* *}$ & $35,56 *$ \\
\hline Solo (4,0 mg dm-3 de $\mathrm{Mn}$ ) & $74,28^{\text {ns }}$ & $82,48^{\text {ns }}$ & $35,81^{*}$ & $41,29^{\text {ns }}$ \\
\hline Solo $\left(8,0 \mathrm{mg} \mathrm{dm}^{-3} \mathrm{de} \mathrm{Mn}\right)$ & $82,52 * *$ & $87,82 *$ & $52,51 * *$ & $49,42 * *$ \\
\hline Solo ( $16,0 \mathrm{mg} \mathrm{dm}^{-3}$ de $\mathrm{Mn}$ ) & $75,40^{\text {ns }}$ & $81,16^{\text {ns }}$ & $40,31^{\text {ns }}$ & $38,38^{\text {ns }}$ \\
\hline DMS & \multicolumn{2}{|c|}{$* *=4,56 ; *=3,62$} & \multicolumn{2}{|c|}{$*=4,17 ; * *=5,25$} \\
\hline
\end{tabular}

**D.M.S. a 1\%; *D.M.S. a 5\% e ns = não significativo. 
o Canastra (Soares et al., 1999). Este resultado controvertido encontra suporte no estudo de Atroch (1999), o qual concluiu ser o cultivar Confiança instável quanto à produtividade de grãos. Outra explicação para esta igualdade de produção média total de grãos cheios, entre as cultivares, neste estudo, pode ser devida ao fato de o cultivar Confiança apresentar maior percentagem de grãos cheios em contrapartida à maior massa de grãos do Canastra (Soares et al., 1999), contrabalanceando a produção total final de ambos os cultivares.

Observando a resposta desses cultivares às doses aplicadas via solo, verifica-se que, apesar da menor produção total de grãos cheios nas menores doses aplicadas, o cultivar Canastra mostrou-se mais responsivo que o Confiança, superando-o a partir da aplicação de $6,81 \mathrm{mg} \mathrm{dm}^{-3}$ de $\mathrm{Mn}$ via solo, sendo a produção máxima alcançada pelo Canastra (aplicação de 9,83 $\mathrm{mg} \mathrm{dm}^{-3}$ via solo) superior à do Confiança (aplicação de $8,75 \mathrm{mg} \mathrm{dm}^{-3}$ via solo) (Figura 2c). Em relação ao modo de aplicação, é observado em mais essa variável quea aplicação via solo de $8 \mathrm{mg} \mathrm{dm}^{-3}$ superou a aplicação foliar para ambos os cultivares (Quadro 4).

Confrontando os dados nos quais houve interação decultivar e adubação (Quadro 4), referentes à aplicação foliar eao tratamento que não recebeu $\mathrm{Mn}$ ( $0 \mathrm{mg} \mathrm{dm}^{-3}$ ), verifica-se, tanto para \% de grãos cheios quanto para a produção total de grãos cheios, que o cultivar Canastra exibiu maior aproveitamento do $\mathrm{Mn}$ pulverizado às folhas. Os resultados deste trabalho vêm, de certa forma, apontar a maior sensibilidade e responsividade do cultivar Canastra ao manganês e corroborar as observações de Reuter et al . (1988) quanto às variações intra-espécies.

Segundo os resultados obtidos com a adubação via solo, observa-se que as características avaliadas foram depreciadas pelas maiores doses de $\mathrm{Mn}$, mesmo com os teores foliares desse nutriente (propiciado por essas maiores aplicações), estando na faixa dita como adequada pela literatura. Assim sendo, buscou-se estabelecer relações entre o $\mathrm{Mn}$ aplicado via solo e teores de outros nutrientes na parte aérea, com o intuito de verificar a ocorrência ou não de possíveis interações.

Apenas os nutrientes N, Ca e Fe foram influenciados pelas doses de $\mathrm{Mn}$ aplicadas via solo, independentemente do cultivar (Figura 3). As faixas de teores foliares adequados para esses nutrientes foram de 26-42 $\mathrm{g} \mathrm{kg}^{-1}, 2,5-4,0 \mathrm{~g} \mathrm{~kg}^{-1}$ e 70-300 mg kg-1, respectivamente (Fageria et al., 1995). Observa-se que, apesar de a adubação com $\mathrm{Mn}$ via solo afetar, pelo menos em algum momento, os teores foliares desses nutrientes, apenas os teores de Fe na parte aérea estão fora da faixa adequada, na faixa crítica (50-70 $\mathrm{mg} \mathrm{kg}^{-1}$ ) para a cultura do arroz, segundo Fageira et al. (1995). Com relação às interações de $\mathrm{Mn}^{+2}$ ecátions dival entes, a menos contestada éa com o Fe. Segundo Malavolta et al. (1997), percebem-se
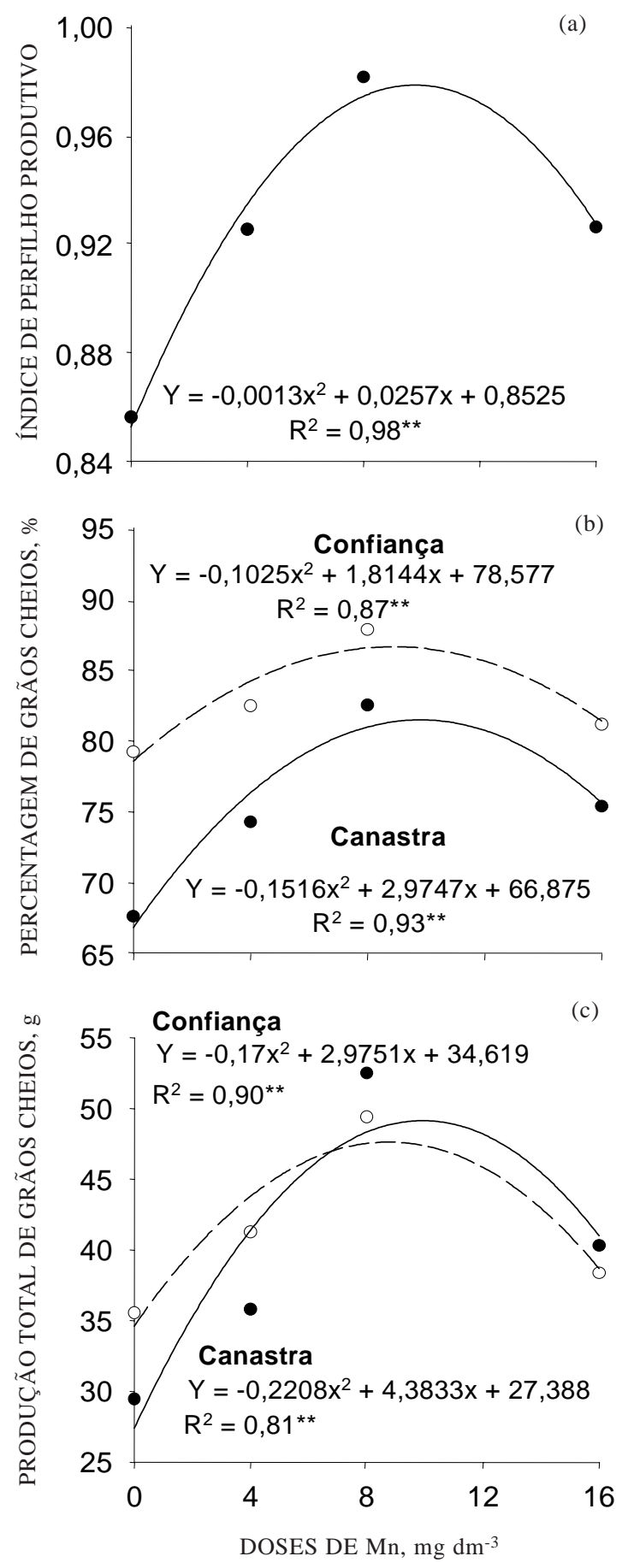

Figura 2. Índice de perfilho produtivo (a), percentagem de grãos cheios (b) e produção total de grãos cheios (c) nos cultivares estudados, considerando as doses de manganês aplicadas ao solo.

fortes evi dências da inibição competitiva entre estes el ementos e, para Ponnamperuma \& Lantin (1985), há possibilidade de se aplicar um desses nutrientes como amenizador da toxidez do outro. 
Os resultados obtidos neste estudo indicam que o efeito da aplicação de Mn sobre as características avaliadas deve ser um resultado da deficiência de Fe ocasionada pela competição com o $\mathrm{Mn}$ e não um efeito fitotóxico do Mn propriamente dito.
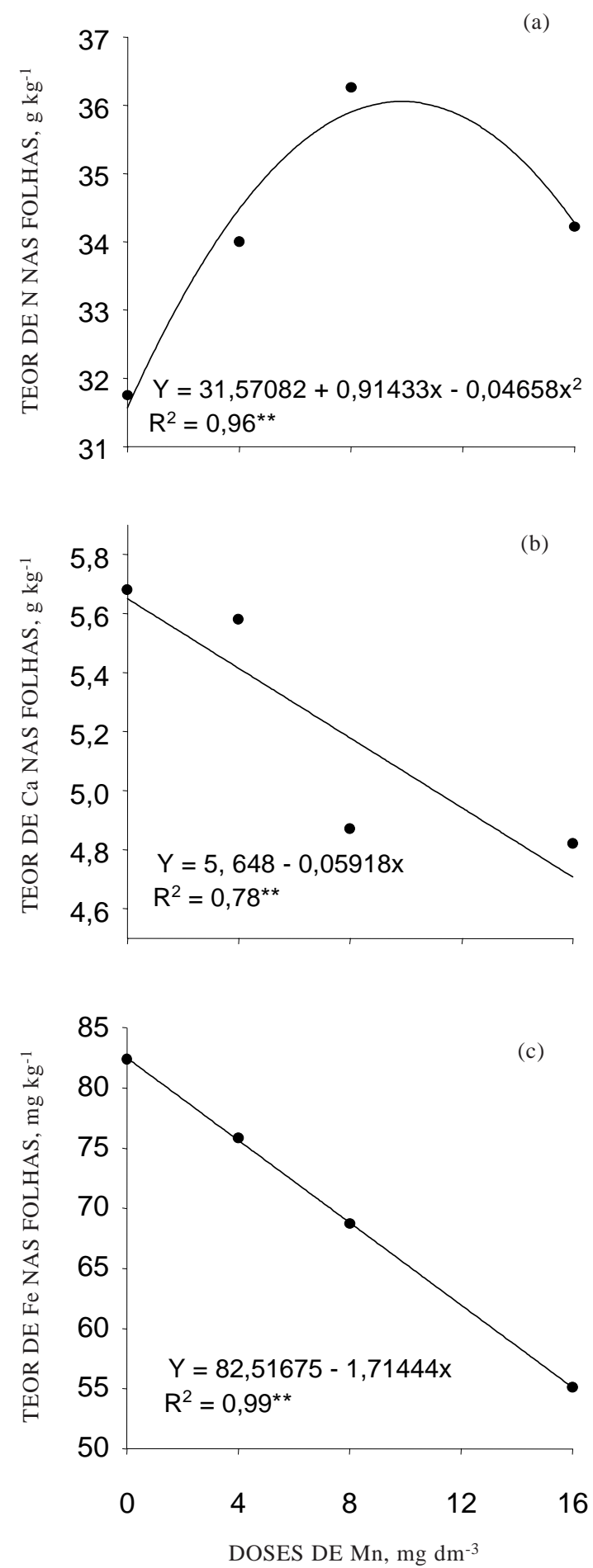

Figura 3. Teores foliares de N (a), Ca (b) e Fe (c) para ambos os cultivares estudados, considerando as doses de manganês aplicadas ao solo.

\section{CONCLUSÕES}

1. A aplicação de $M n$ via solo propiciou os maiores incrementos nos valores das variáveis estudadas, sendo esse o modo de fertilização recomendado.

2. As máximas produções das variáveis foram obtidas entre 8,75 e 9,93 $\mathrm{mg} \mathrm{dm}^{-3}$ de $\mathrm{Mn}$ aplicado via solo, evidenciando que a dose recomendada pela literatura de $8 \mathrm{mg} \mathrm{dm}^{-3}$ mostrou-se adequada.

3. O cultivar Canastra foi mais responsivo à adubação com Mn que o Confiança, apresentando maior produção de grãos cheios a partir da aplicação de 6,81 $\mathrm{mg} \mathrm{dm}^{-3}$ de $\mathrm{Mn}$ via solo.

4. O efeito negativo das maiores doses de $\mathrm{Mn}$ aplicadas via solo sobre as caracteríscas avaliadas deveu-se à deficiência de Fe e não à toxidez de Mn propriamente dita.

\section{LITERATURA CITADA}

ATROCH, A.L. Adaptabilidade e estabilidade de linhagens de arroz de sequeiro avaliadas em Minas Gerais no período de 1993/94 a 1995/96. Lavras, Universidade Federal de Lavras, 1999. 67p. (Tese de Mestrado)

BANZATTO, D.A. \& KRONKA, S.N. Experimentação agrícola. J aboticabal, Universidade Estadual de São Paulo, 1992. 247p.

BARBOSA FILHO, M.P. \& FAGERIA, N.K. Ocorrência, diagnose e correção da deficiência de zinco na cultura de arroz de sequeiro. Goiânia, Empresa Brasileira de Pesquisa Agropecuária/CNPAF, 1980. 18p. (Circular Técnica, 4)

BARBOSA FILHO, M.P. Nutrição e adubação do arroz: sequeiro e irrigado. Piracicaba, POTAFOS, 1987. 129p. (Boletim Técnico, 9)

CLARKSON, D.T. The Uptake and translocation of Manganese by Plant Roots. In: GRAHAM, R.D.; HANNAM, R.J . \& UREN, N.C., eds. Manganese in soils and plants. Netherlands: Kluwer Academic,1988. p.101-111.

EMPRESA BRASILEIRA DE PESQUISA AGROPECUÁRIA EMBRAPA. Centro Nacional de Pesquisa de solos. Manual de métodos de análise de solo. Rio de J aneiro, 1997. 212p.

FAGERIA, N.K.; FERREIRA, E.; PRABHU, A.S.; BARBOSA FILHO, M.P. \& FILIPPI, M.C. Seja doutor do seu arroz. Piracicaba, Potafos, 1995. 20p. (Arquivo do Agrônomo, 9)

FORNASIERI FILHO, D. \& FORNASIERI, J.L. Manual da cultura do arroz. J aboticabal, FUNEP, 1993. 221p.

HANNAM, R.J . \& RIGGS, J .L. The effect of manganese applied from an aircraft as a low-volume foliar spray in preventing manganese deficiency in Lupinus angustifol ius L. Fert. Res., 6:149-156, 1985.

INSTITUTO BRASILEIRO DE GEOGRAFIA E ESTATÍSTICA - IBGE. Levantamento sistemático da produção agrícola. Belo H orizonte, Departamento Regional Sudeste-2/Divisão de Pesquisa de Minas Gerais,1999. p.7-8. 
ISHIZUKA, Y. Physiology of the rice plant. Adv. Agron., 23:241315, 1971.

LONERAGAN, J.F. Distribution and movement of Manganese in plants In: GRAHAM, R.D.; HANNAM, R.J . \& UREN, N.C., eds. Manganese in soils and plants. Netherlands, Kluwer Academic,1988. p.113-124.

LONGNECKER, N.E.; GRAHAM, R.D. \& CARD, G. The effect of manganese deficiency on growth and devel opment of barley (Hordeum vulgare, L.). Aust. Soc. Plant Physiol., 28:85-102, 1988.

LOPES, A.S. \& GUILHERME, L.R.G. Solos sob cerrado: manejo da fertilidade para produção agropecuária. São Paulo, Anda, 1994. 62p. (Boletim Técnico, 5)

MALAVOLTA, E.; VITTI, G.C. \& OLIVEIRA, S.A. Avaliação do estado nutricional das plantas: princípios eaplicações. 2.ed. Piracicaba, POTAF OS, 1997. 319p.

MANN, E.N. Efeito da adubação com manganês, via solo e foliar em diferentes épocas, no rendimento de grãos e na qualidade da semente de soja. Lavras, U niversidade Federal de Lavras, 1999. 68 p. (Tese de Mestrado)

NEVES, J .C.L. Micronutrientes. Brasília, ABEAS, 1994. 26p. (Curso de Fertilidade e Manejo do Solo)
PONNAMPERUMA, F.N. \& LANTIN, R.S. Diagnoses and amelioration of nutritional disorders of rice. Los Baños, IRRI, 1985. 20p.

RAIJ , B. van.; CANTARELA, H.; QUAGGIO, J.A. \& FURLANI, A.M.C. Recomendações de adubação e cal agem para o estado de São Paulo, 2.ed. Campinas, Instituto Agronômico \& Fundação IAC, 1996. 285p. (Boletim técnico, 100)

REUTER, D.J .; ALSTON, A.M. \& MCFARLANE, J .D. Occurence and Correction of Manganese Deficiency in Plants. In: GRAHAM, R.D.; HANNAM, R.J . \& UREN, N.C., eds. Manganese in soils and plants. Netherlands, Kluwer Academic, 1988. p.205-218.

SANZONOWICZ, C. Deficiência de manganês em solos dos cerrados. In: YAMADA, T., ed. Informações agronômicas. Piracicaba, POTAFOS,1995. p.7. (Boletim, 71)

SOARES, A.A.;VIEIRA, R.V.; SOUZA, A.F. Canastra e Confiança: arroz agulhinha para plantio em condições de sequeiro e sob pivô central. Lavras, EPAMIG/UFLA/EMBRAPA/UFV, 1999. 6p. (Folder)

TOLEDO, L.R. Arroz: sequeiro molhado. Globo Rural, 164:4246, 1999.

ZONTA, E.P. \& MACHADO, A.A. Manual do SANEST: sistema de análise estatística para microcomputadores. Pelotas, Universidade Federal de Pelotas, 1991. 102p. 
G.D. PEREIRA et al. 